\title{
Lab-scale investigation on remediation of diesel-contaminated aquifer using microwave energy
}

Pietro P. Falciglia ${ }^{1, *}$, Riccardo Maddalena ${ }^{1}$, Giuseppe Mancuso $^{2}$, Valeria Messina ${ }^{1}$, Federico G.A. Vagliasindi ${ }^{1}$

${ }^{1}$ Department of Civil Engineering and Architecture - University of Catania. Via S. Sofia, 64 - 95125 Catania, Italy

${ }^{2}$ Department of Civil, Environmental and Mechanical Engineering - University of Trento. Via Mesiano, 77 38123 Trento, Italy

*Corresponding author: ppfalci@ dica.unict.it

\begin{abstract}
Aquifer contamination with diesel fuel is a worldwide environmental problem, and related available remediation technologies may not be adequately efficient, especially for the simultaneous treatment of both solid and water phases. In this paper, a lab-scale $2.45 \mathrm{GHz}$ microwave (MW) treatment of an artificially diesel-contaminated aquifer was applied to investigate the effects of operating power (160, 350 and $500 \mathrm{~W}$ ) and time on temperature profiles and contaminant removal from both solid and water phases. Results suggest that in diesel-contaminated aquifer MW remediation, power significantly influences the final reachable temperature and, consequently, contaminant removal kinetics. A maximum temperature of about $120^{\circ} \mathrm{C}$ was reached at $500 \mathrm{~W}$. Observed temperature values depended on the simultaneous irradiation of both aquifer grains and groundwater. In this case, solid phase heating is limited by the maximum temperature that interstitial water can reach before evaporation. A minimal residual diesel concentration of about $100 \mathrm{mg} \mathrm{kg}^{-1}$ or $100 \mathrm{mg} \mathrm{L}^{-1}$ was achieved by applying a power of $500 \mathrm{~W}$ for a time of $60 \mathrm{~min}$ for the solid or water phase, respectively. Measured residual TPH fractions showed that MW heating resulted in preferential effects of the removal of different TPH molecular weight fractions and that the evaporation-stripping phenomena plays a major role in final contaminant removal processes. The power low kinetic equation shows an excellent fit $\left(r^{2}>0.993\right)$ with the solid phase residual concentration observed for all the powers investigated. A maximum diesel removal of 88 or $80 \%$ was observed for the MW treatment of the solid or water phase, respectively, highlighting the possibility to successfully and simultaneously remediate both the aquifer phases. Consequently, MW, compared to other biological or chemical-physical treatments, appears to be a better choice for the fast remediation of diesel-contaminated aquifers.
\end{abstract}

Keywords: Aquifer; diesel fuel; groundwater; microwave; remediation. 


\section{Introduction}

Hydrocarbon-pollution in soil and groundwater is usually related to accidental leaks during handling, transport or storage activities, all of which constitute a serious environmental issue worldwide (Careghini et al., 2015; Mena et al., 2015). In most cases, released petroleum products form nonaqueous phase liquids (NAPLs), which then become the long-term source of aquifer contamination. Among hydrocarbons, diesel fuel is a complex mixture of saturated and polycyclic-aromatichydrocarbons (PAHs) which, due to its extensive use worldwide, is a permanent source of contamination (Jagtap et al., 2014; Pazos et al., 2012; Silva-Castro et al., 2013; Tatáno et al., 2013).

It is well known that conventional methods such as pump-and-treat are ineffective for treating the contamination source or in removing total petroleum hydrocarbons (TPHs) from the aquifer due to the hydrocarbon low solubility in water and the heterogeneity of the sites (Liang et al., 2011). Regarding alternative methods, there are a number of in situ biological/chemical techniques such as air- or biosparging (AS/BS), in situ chemical oxidation (ISCO) or permeable reactive barriers (PRBs). In situ biodegradation is classified as a cost-effective and eco-friendly treatment to remove TPHs from contaminated aquifers due to its ability to produce minimal amounts of toxic secondary by-products (Hunkeler et al., 2002). However, the effectiveness of the process depends on many factors such as contamination nature, presence of microorganisms able to biodegrade the contaminants or the absence of toxic substances, all of which generally result in very long remediation times (Garoma et al., 2008). Moreover, in situ biodegradation is neither suitable in cases of high levels of hydrocarbon contamination or free phase due to its toxicity to microorganisms (Oya and Valocchi, 1998). ISCO involves the application of various combinations of agents such as $\mathrm{O}_{3}$ or $\mathrm{H}_{2} \mathrm{O}_{2}$ and is able to oxidize a wide variety of organic pollutants into intermediates and end-products. Despite its advantage of a rapid reaction rate, the chemical oxidation process may create some toxic or mobile by-products that can potentially limit its in situ application especially in the presence of groundwater (Kim and Lee, 2012). PRBs have received a great deal of attention as an innovative method for in situ contaminated groundwater remediation (Bortone et al., 2013; Careghini et al., 2015; Xin et al., 2013); however, 
these allow for only a passive plume control and are unsuitable for the direct treatment of the contamination source or the remediation of small sites such as petrol stations (Liang et al., 2011). Therefore, it is necessary to widen the boundaries related to alternative remediation methods for TPH removal from aquifers and to diesel fuel in particular (Fan et al., 2014).

In recent years, microwave $(\mathrm{MW})(\mathrm{f}=2.45 \mathrm{GHz})$ heating remediation has attracted great attention in the environmental field. MW energy adsorbed by a contaminated matrix is converted into heat and, consequently, into a temporal increase $\left(\Delta T \Delta t^{-1},{ }^{\circ} \mathrm{C} \mathrm{min}^{-1}\right)$ of the matrix temperature as defined in the Eq. 1 (Falciglia et al., 2013)

$$
\frac{\Delta \mathrm{T}}{\Delta \mathrm{t}}=\frac{\mathrm{P}}{\mathrm{c}_{\mathrm{p}} \cdot \rho}=\frac{\omega \cdot \varepsilon_{0} \cdot \varepsilon "|\mathrm{E}|^{2}}{\mathrm{c}_{\mathrm{p}} \cdot \rho}
$$

where $P$ is power absorbed per unit volume $\left(\mathrm{W} \mathrm{m}^{-3}\right), \omega$ is the angular frequency, $\varepsilon_{0}$ is the permittivity of free space $\left(8.85 \cdot 10^{-12} \mathrm{~F} \mathrm{~m}^{-1}\right), E$ is the internal electric field $\left(\mathrm{V} \mathrm{m}^{-1}\right), c_{p}$ is the heat capacity of the matrix $\left(\mathrm{KJ} \mathrm{kg}^{-1}{ }^{\circ} \mathrm{C}^{-1}\right)$ and $\rho$ is its density $\left(\mathrm{kg} \mathrm{m}^{-3}\right) . \varepsilon^{\prime \prime}$ is defined as dielectric loss factor, and it represents the ability of a material to convert the MW energy into heat. MW energy was shown to be effective as a remedial alternative for contaminated soils (Falciglia et al., 2013; Robinson et al., 2012), sludge (Barba et al., 2012; Tyagi and Lo, 2013), drilled cuttings (Pereira et al., 2014), or electric arc furnace dust (Al-harahsheh et al., 2014).

MW treatments were reported to be efficient in a short time for the removal of a large number of volatile and semi-volatile contaminants such as polychlorobiphenyls (PCBs) (Gomes et al., 2013), hexachlorobenzene (HCB) (Yuan et al., 2006), polycyclic aromatic hydrocarbons (PAHs) (Robinson et al., 2009), crude oil (Li et al., 2009), antibiotics (Lin et al., 2010) or diesel-fuel (Falciglia et al., 2013, Falciglia and Vagliasindi, 2014, 2015a). Several studies, aimed at investigating pilot-scale in situ or ex-situ MW application, have been recently performed by Barba et al. (2011), Chien (2012) and Buttress et al. (2016). The overall advantages of microwave heating are: short time, effective and homogeneous heating, high flexibility, improved ease of risk control, automatic control of the heating processes (Benedetto and Calvi, 2013). In fact, MW heating is based on the direct interaction of the microwave with the contaminated matrix. This consequently allows conventional heating limitations 
to be overcome, which in turn leads to a reduction of treatment time, risk of further contamination and costs (Falciglia and Vagliasindi, 2014).

In addition, as the amount of water increases, so does MW removal efficiency due to its MW absorbing features and the possibility to activate contaminant-stripping phenomena (Falciglia et al., 2013; Robinson et al., 2014). This highlights the possibility of reaching a high MW absorbing phase for a contaminated aquifer for which water is highly present. Despite the MW heating ability and current knowledge about its environmental implications, studies on the potential in situ MW applicability for the treatment of hydrocarbon-contaminated aquifers have not been undertaken. The necessity of the simultaneous treatment of both solid (grains of the aquifer skeleton) and interstitial water (groundwater) phases, makes the problem more complex, this also being due to the different abilities of the two aquifer phases to absorb and convert MW energy as well as their physical interactions with contaminants. This study was performed to fill this knowledge gap.

The main objective of the work is to study the contaminant removal processes and the potential MW treatability of an aquifer contaminated with diesel fuel by assessing the influence of power and heating time on the temperature profiles and the TPH fraction contaminant removal kinetics of solid and water phases. Lab-scale experiments were conducted with the purpose of fulfilling the objective.

\section{Materials and methods}

\subsection{Materials}

Diesel fuel (Esso, Italy) was used to artificially contaminate the lab-scale aquifer. Contaminant properties are reported in Falciglia and Vagliasindi (2015a). All chemicals used in this work were of analytical reagent quality. n-Hexane $\left(\mathrm{C}_{6} \mathrm{H}_{14}\right.$, purity $\left.99 \%\right)$ was purchased from Merck $\mathrm{KGaA}$ (Darmstadt, Germany). The lab-scale aquifer was simulated using a model silica sand $(0.05-1.00$ $\mathrm{mm}$ ) free of anthropogenic contamination (Table 1) and deionised water. Activated carbons used for the volatile compounds (VOCs) capture system present in the experimental setup were supplied by Norit Italia S.p.A. (Italy).

\subsection{Contamination procedure}


The contamination procedure was performed by mixing a diesel-hexane solution with selected sand samples. Sand and pollutant solution were shaken for $48 \mathrm{~h}$ using an orbital shaker, then the solvent was removed in $1 \mathrm{~h}$ applying a slight vacuum by means a rotary evaporator. The contaminated sand was kept in a closed vessel and stored for 1 month, then was saturated with deionised water and stored in a dark room at $4{ }^{\circ} \mathrm{C}$ for 4 months in order to maximize the interaction of contaminant with both the solid and water phases and then to obtain representative samples of a real contaminated aquifer. The porosity of the sand was determined using the method applied by Folch et al. (2013). After the equilibration period, ten representative aquifer samples were collected. The water phase was separated by sand grains using a Büchner funnel under a slight vacuum; then the aquifer solid and water phases were analysed for initial TPH content $\left(C_{0}\right)$. Based on preliminary results of this work, a $C_{0}$ value of $812 \mathrm{mg} \mathrm{kg}^{-1}$ and $575 \mathrm{mg} \mathrm{L}^{-1}$ was considered for the solid and water phase, respectively. Such high contamination levels were selected so as to represent a "worst-case" scenario.

\subsection{Lab-scale MW experiments}

In this study, lab-scale experiments were performed to evaluate the effectiveness of a MW treatment of a diesel-polluted aquifer. Selected contaminated samples were treated simulating in situ MW heating conditions by using an experimental apparatus operating at $2.45 \mathrm{GHz}$. Schematic of the labscale apparatus used for the experiments is shown in Figure 1. A cylindrical quartz reactor was installed in the centre-section of the MW oven cavity and filled with $625 \mathrm{~g}$ of contaminated model aquifer (425 g of solid - $200 \mathrm{~g}$ of saturation water). A thermocouple system was installed for the temperature $(T)$ measurement in three points of the aquifer sample. A peristaltic pump was used to deliver the water needed for the replacement of the saturated water evaporated during the irradiation process. The gas outlet section of the reactor was connected to a VOC (mainly $\mathrm{CO}, \mathrm{CO}_{2}, \mathrm{CH}_{4}, \mathrm{C}_{2} \mathrm{H}_{2}$, $\mathrm{C}_{2} \mathrm{H}_{6}$ ) capture/treatment system made by a condensing unit, an activated carbon filter and a vacuum pump.

Twenty-one experiments were performed irradiating the artificial aquifer in a continuous mode for a time of either 5, 18, 30 or $60 \mathrm{~min}$, using applied power values of 160,350 or $500 \mathrm{~W}$. At the beginning of the heating treatment, the pump was turned on to introduce deionised water into the aquifers. 
Different constant inflow rates (Table 2), depending on the operating power $(P)$, were flushed though the system. Inflow rate values were determined in preliminary tests where the previous irradiation conditions were considered. Three different temperature $(T)$ values were measured in the aquifer system and mean values were shown. After treatment, aquifer samples were removed from the apparatus, cooled at room temperature $\left(20^{\circ} \mathrm{C}\right)$ and stored in a dark room at $4{ }^{\circ} \mathrm{C}$ prior to analysis. For each thermal treatment, the procedure was carried out in triplicate and mean values of residual diesel concentrations $(C)$ were obtained for both selected power $(P)$ and time $(t)$ and for aquifer solid and water phases as well. Contaminant removal $(R)$ was also calculated according to the following expression:

$$
\mathrm{R}_{\%}=\frac{\mathrm{C}_{0}-\mathrm{C}}{\mathrm{C}_{0}} \cdot 100
$$

\subsection{Analytical procedures}

In this study, the concentration of TPHs having carbon numbers of 12-50 $\left(\mathrm{C}_{12}-\mathrm{C}_{50}\right)$ in solid and water phases before (initial concentration, $C_{0}$ ) and after the treatment (residual concentration, $C$ ) was taken, as was that of diesel fuel, expressed as $\mathrm{mg} \mathrm{kg}^{-1}$. The $\mathrm{TPH}$ concentration was measured by gas chromatography (GC) (Perkin Elmer Clarus 600) equipped with a flame ionization detector (FID) and a capillary Zebron ZB5MS column $(30 \mathrm{~m}$ in length, $0.25 \mathrm{~mm}$ in diameter and $0.25 \mu \mathrm{m}$ in film thickness (Phenomenex). EPA 3540C, EPA 8015D and EPA 3510C, EPA 8015D methods were used for TPH analysis of solid and liquid phases, respectively. The GC was operated with helium $(99.99 \%$ purity) as carrier-gas flow at a rate of $4 \mathrm{~mL} \mathrm{~min}^{-1}$ and the oven temperature programme began at $50{ }^{\circ} \mathrm{C}$ (held for $1 \mathrm{~min}$ ) and increased at a rate of $20^{\circ} \mathrm{C} \mathrm{min}^{-1}$ to a maximum temperature of $340{ }^{\circ} \mathrm{C}$. The temperature of the injector was $320^{\circ} \mathrm{C}$.

\section{Results and discussion}

\subsection{Temperature profiles}

Three levels of MW power, 160, 350 and $500 \mathrm{~W}$ were investigated and the temperature $(T)$ of the aquifer was measured with time as shown in Figure 2. For all the conditions, $T$ increased with increasing power. Initially, temperature increased rapidly and stabilised after $18 \mathrm{~min}$. For the lowest 
and intermediate power investigated of 160 and $350 \mathrm{~W}, T$ values of 102 and $110{ }^{\circ} \mathrm{C}$ were observed, respectively, at the end of the treatment. A maximum temperature of about $120{ }^{\circ} \mathrm{C}$ was reached at 500 $\mathrm{W}$ irradiation. The main cause of the thermal effect of MW irradiation is the ability of the aquifer system to convert electromagnetic energy into heat due to the dielectric polarisation of the particles in an alternating electric field. The main heating mechanisms of MW are dipolar polarisation, conduction mechanism and interfacial polarisation. For the first mechanism, when dipoles forming the polar substances are immersed in a high-frequency alternating electric field such as the MW $(2.45 \mathrm{GHz})$ one, the continuous dipole rotation can not adequately follow the rate of change of direction of the electric field generated by radiation. This leads to a time delay and, consequently, to a substantial quantity of energy being turned into heat (Remya and Lin, 2011). On the other hand, in conventional thermal processing the heat is transferred to the material by thermal gradient based convection, conduction and radiation mechanisms from the surfaces of the material, whereas in MW heating, microwave energy is delivered directly to materials through molecular agitation (Benedetto and Calvi, 2013). Previous studies on MW heating of silica sandy soil have reported a similar trend but with a maximum temperature value of about $240{ }^{\circ} \mathrm{C}$, obtained by applying similar experimental conditions $(\mathrm{P}$ $=600 \mathrm{~W}, \mathrm{t}=60 \mathrm{~min}$ ) (Falciglia et al., 2013). In this case, the behaviour for which the temperature rises more rapidly when the treatment starts and tends after to stabilise is due to a reduced ability of the MW absorbent medium to convert energy into heat. It was found that for moisturised silica sand, the dielectric loss factor $\varepsilon^{\prime \prime}$ decreases with an increase in temperature for temperature values lower than $200{ }^{\circ} \mathrm{C}$ (Falciglia and Vagliasindi, 2015a; Robinson et al., 2012). This finding has been also confirmed by other researchers. Li et al. (2009) reported a maximum temperature of about $200{ }^{\circ} \mathrm{C}$ reached during a $10 \mathrm{~min}$ - MW treatment of a crude oil-polluted soil at $800 \mathrm{~W}$. Analogue temperature profiles were also reported by Diprose (2001) and Lin et al. (2010). However, in these investigated systems, the presence of water is only temporarily due to the evaporation phenomena caused by irradiation, which leads to a continuous transformation of energy into a temperature increase until $\varepsilon^{\prime \prime}$ reaches minimal values, thus making the overall temperature of the irradiated matrix almost constant with heating time. 


\subsection{Kinetics of diesel removal}

\subsubsection{Contaminant removal from solid phase}

Figure 3 shows the dynamics of residual diesel concentration $(C)$ adsorbed on the solid phases (aquifer grains) represented by TPHs $\left(\mathrm{C}_{12}-\mathrm{C}_{50}\right)$ with time, at the three investigated powers. $C$ decreased with time and the rate of contaminant desorption increased with the power applied. A minimal $C$ value of about $100 \mathrm{mg} \mathrm{kg}^{-1}$ was achievable by applying a power of $500 \mathrm{~W}$ for a treatment time of $60 \mathrm{~min}$, whereas the contaminant concentration was only halved (about $400 \mathrm{mg} \mathrm{kg}^{-1}$ ) by using the lowest power of $160 \mathrm{~W}$. Several factors can influence the hydrocarbon removal efficiency of MW system including MW power and irradiation time. Generally, the efficiency of the MW system increases gradually with increase in MW power and irradiation time. This could be attributed to the generation of additional heat, which favours impetuous and rapid molecular motion (Remya and Lin, 2011). Longer MW radiation time induced a higher temperature, which subsequently induced more impetuous molecule motion and faster contaminant transfer and benefited the elimination of diesel. Since the diesel was removed mostly at high temperature in our study, it could be deduced that thermal effect influenced the contaminant removal.

For a conventional or MW thermal desorption process, residual hydrocarbon concentration curves as a function of the heating time follow a nonlinear exponential decay (Falciglia et al., 2011b; Falciglia and Vagliasindi, 2015b) expressed by the follow equation:

$$
\mathrm{C}=\mathrm{C}_{0} \mathrm{e}^{-\mathrm{kt}{ }^{\mathrm{n}}}
$$

where $\mathrm{C}$ is expressed as a function of the initial hydrocarbon concentration $\left(C_{0}\right)$, the heating time $(t$, $\min )$, the rate of decay $\left(k, \min ^{-1}\right)$ and the shape of the decay curve $(n) . k$ depend on temperature and the activation energy of the system. Contaminant residual concentration values $(C)$ obtained during the experiments were fitted using the kinetic model expressed by Eq. 3. From best fitting curve problem solving, desorption parameters $k$ and $n$ were calculated for each power investigated and the correlation was assessed as correlation coefficient $r^{2}$. 
An excellent fit was obtained resulting in a correlation coefficient $\left(r^{2}\right)$ higher than 0.993 in all cases (Figure 3). In addition, rate of decay $(k)$ increased linearly with the operating power $P(k=0.0003 \mathrm{P}+$ $\left.0.175 ; r^{2}=0.976\right)$. A very similar kinetic $\left(k=0.0003 \mathrm{P}+0.111 ; \mathrm{r}^{2}=0.977\right)$ (Figure 4$)$ was reported in our previous study (Falciglia and Vagliasindi, 2015a) treating a diesel-contaminated sandy soil (moisture 10\%) at $600 \mathrm{~W}$ power for $60 \mathrm{~min}$.

However, although temperature did in fact influence the contaminant removal process, overall, the observed diesel removals clearly demonstrate that in the presence of a high water content, the maximum temperature of the irradiated matrix does not represent the only factor in the remedial process and that residual contaminant concentration does not strictly depend on the maximum temperature that the system reaches during the MW treatment. In fact, it was previously demonstrated that temperatures higher than $180-200{ }^{\circ} \mathrm{C}$ are generally needed in order to obtain minimal residual diesel concentrations on solid matrices. Therefore, the evaporation-contaminant stripping phenomena present a major influence on the removal of contaminants. Kinetic data obtained are also in agreement with other authors who have investigated the use of MW for hydrocarbon removals from polluted soils (Huang et al., 2011; Liu and Yu, 2006).

Knowing how residual contaminant concentration values act as a function of power and heating time is fundamental in scaling-up desorption systems and assessing the effectiveness of the remedial treatment. In fact, experimental parameters $k$ and $n$ assessed for the different powers investigated are of practical interest and could represent a valuable tool in calculating the residual concentration or desorption rate at any given initial soil concentration and in identifying the power and the time of treatment required to reach specific targeted levels of remediation.

\subsubsection{Contaminant removal from water and TPH fraction distribution}

Diesel concentration $\left(C_{0}\right)$ initially adsorbed on aquifer grains before the heating treatment was measured as TPH fractions $\left(\mathrm{C}_{12}-\mathrm{C}_{50}\right)$ and a related percentage was calculated as the ratio between the concentration of the single TPH fraction and the total concentration $\mathrm{C}_{12}-\mathrm{C}_{50}$. Results are given in Table 3. For the solid phase, the percentage distribution of single TPH fractions adsorbed before the treatment increased with a decrease in the hydrocarbon molecular weight, clearly indicating that 
contaminant fractions did not adsorb at the same way onto the aquifer grains. However, this distribution changed in the water phase. Despite the fact that the TPH fractions increased with a decrease in molecular weight as in the previous case, the highest molecular weight fraction $\left(\mathrm{C}_{40}-\mathrm{C}_{50}\right)$ was not detected in the liquid phase. This was due to the reduction of hydrocarbons in water solubility with an increase in the molecular weight and the complexity of the molecular structure (Mackay et al., 2006).

Residual diesel concentration $(C)$ in water and the TPH fraction distribution in solid and liquid phases after the MW treatment are reported in Figure 5 and Tables 4 and 5, respectively. As previously reported, MW energy that was adsorbed by silica grains and interstitial water resulted in a global increase of aquifer temperature. This led to the evaporation of contaminants adsorbed onto the solid matrix and water jointly with dissolved hydrocarbon. Hydrocarbons, initially dissolved in water, were removed with vapour whereas hydrocarbon fractions, initially adsorbed onto solid phase, were first moved into water and after removed by evaporation phenomena. This contaminant transfer is clearly shown in Figure 5, where a relative increase of hydrocarbon concentration is evident in water after the first $5 \mathrm{~min}$. However, treatment times higher than $5 \mathrm{~min}$ resulted in a significant reduction of contaminant initially present in water $\left(575 \mathrm{mg} \mathrm{L}^{-1}\right)$ up to minimal residual concentration of about 100 $\mathrm{mg} \mathrm{L}^{-1}$ in the case of the highest power application. Specifically, the gradual increase in the aquifer temperature resulted in a preferential effect of the thermal treatment on the various TPHs adsorbed onto solids. MW treatment produced a major desorption of the lightest TPH fractions with the range of TPH fractions removed depending on the heating time and on the aquifer temperature as well. This becomes more evident by observing the reduction of the percentage of $\mathrm{C}_{12}-\mathrm{C}_{20}$ TPHs with time and applied power increase (Table 4). Data indicate a major desorption of the lightest TPH fractions probably due to both the temperature increase and evaporation-contaminant stripping phenomena, which present a major influence on the more volatile contaminant fractions. Progressively, the evaporation of the lightest TPH fractions produced a solubilisation and consequently an extraction of the heaviest fractions that were removed, this also being due to the physical phenomena of water vapour stripping. Hence, lighter hydrocarbon fractions act as solvents for those that are heavier. In 
addition, the presence of a vapour stream leads to an increase of vapour pressure resulting in a reduction of the temperature needed for the contaminant desorption and consequently in an increase in removal efficiency.

As reported in Table 5, a decrease of the lightest TPH fractions $\left(\mathrm{C}_{12}-\mathrm{C}_{20}\right)$ occurred with treatment time and power increase, whereas the higher fractions $\left(\mathrm{C}_{20}-\mathrm{C}_{30}\right.$ and $\left.\mathrm{C}_{30}-\mathrm{C}_{40}\right)$ increased. This is due to the highest ability of these compounds to form dispersed micro-aggregates in water after their removal from the solid phase, all of which plays a major role in the presence of low soluble compounds such as TPHs. Lightest fractions, after their transfer from the solid to liquid phase, were removed by stripping or tended towards a re-adsorption onto solids, whereas the higher fractions formed micro dispersions less removable from water. The higher the compound molecular weight, the stronger the tendency to form hydrophobic dispersed-molecular aggregates and the lower the tendency to be re-adsorbed onto aquifer grains.

Based on contaminant residual concentration $(C)$, diesel removal $(R)$ vs. irradiation time was calculated for both the solid and water aquifer phase. Results are shown in Figures 6 and 7, respectively. It is clear that the higher MW powers lead to the higher remediation efficiency and that the trend previously observed for $C$ values vs. time is now reflected to the percentage removal curve shape. Specifically, in the case of the contaminated aquifer grains, a removal of 51,70 and $88 \%$ was observed when the maximum treatment time was investigated and for an operating power of 160,350 or $500 \mathrm{~W}$, respectively. In the case of contaminated interstitial water, removal values of 56, 67 and 80 $\%$ were recorded, considering the same operating conditions. It is important to observe that, despite the low temperature achievable during the remediation treatment, MW heating was very effective for the removal of diesel from both solid and water aquifer phases due to evaporation and stripping phenomena. Based on preliminary results of this study reporting removal percentage in the range 80 $100 \%$ for water contamination levels in the range $2-575 \mathrm{mg} \mathrm{L}^{-1}$ (lower than that investigated here), the possibility of reaching TPH removals higher than $80 \%$ and, consequently, residual contamination 
levels much lower than $100 \mathrm{mg} \mathrm{L}^{-1}$, in the order of few $\mathrm{mg} \mathrm{L}^{-1}$ or hundreds of $\mu \mathrm{g} \mathrm{L}^{-1}$ must be highlighted.

\subsubsection{Comparison between MW efficiency and cost in contaminated soil and aquifer}

Diesel removal $(R)$ data obtained from experiments agree with previous literature findings on MW (Falciglia et al., 2013; Kawala and Atamańczuk, 1998; Robinson et al., 2009) where authors reported that in the presence of low-polar pollutants in soil such as gasoline or diesel-fuel, the main removal process is not based on the selective heating of the contaminants but on their thermal desorption due to the increase of the temperature system and on mechanisms ascribable to a distillation process. The comparison of the removals from solid phase with the results from previous experiments based on the MW treatment of diesel-polluted soils shows that the presence of a much higher amount of water leads to a minimal reduction of the maximum removal achievable considering similar operating conditions. In our previous bench-scale work (Falciglia et al., 2013), we investigated the influence of the applied power variation $(100-1000 \mathrm{~W})$ on soil temperature and hydrocarbon contaminant removal. Results revealed, for example, that the application of powers of 440 and $600 \mathrm{~W}$ for $60 \mathrm{~min}$ led to a total evaporation of the initial water content $(12 \%)$ present in soil as moisture and to a final soil temperature of about 190 and $240{ }^{\circ} \mathrm{C}$, respectively. In contrast, for the aquifer system investigated in this work, the evaporated water is continuously replaced by an input flow able to maintain the water content at a constant level (32\%). This results in a limitation of the $T$ increase due to the maximum $T$ value reachable by the water phase before its evaporation. A final aquifer maximum $T$ value of about $120{ }^{\circ} \mathrm{C}$ was in fact recorded for a 60 min-application of a $500 \mathrm{~W}$-power. When aquifer grains and groundwater are mixed together and irradiated by MW, grains, which could potentially reach $T$ of about $200{ }^{\circ} \mathrm{C}$, are cooled down by interstitial water with a temperature gradient from solid particles to the water phase, although this is difficult to measure. In other words, grains absorb concentrated MW energy and act as "hot spots", yet the maximum temperature reachable by water before evaporation limits MW effects on final global temperature. 
Despite the marked difference of temperature observed for the two different systems (soil and aquifer), a maximum contaminant removal of $89 \%$ was achieved by applying a power of $600 \mathrm{~W}$, whereas a slight lower maximum removal of $88 \%$ was obtained for solid phase (this work), even when considering a lower power of $500 \mathrm{~W}$ application. This is due to the presence of a higher amount of water able to enhance the stripping phenomena and consequently balance the reduction in direct thermal desorption effects. This comparison clearly highlighted the possibility of achieving energy costs for aquifer remediation lower than those needed for soils.

This is in accordance with the study by Barba et al. (2012), where authors showed a maximum temperature of about $100{ }^{\circ} \mathrm{C}$ for sludge $\left(1.86 \mathrm{~kg} \mathrm{H}_{2} \mathrm{O} / \mathrm{kg}\right.$ dry solid) irradiated at a power of $1.90 \mathrm{~kW}$ for a total time of $30 \mathrm{~min}$. This concept is also confirmed by Quan et al. (2007), who reported temperature values slightly higher than $100{ }^{\circ} \mathrm{C}$ for a solution of water and activated carbons (AC) (20 $\mathrm{ml}$ of water $+12.5 \mathrm{~g}$ of $\mathrm{AC}$ ) irradiated using $800 \mathrm{~W}$ power, despite the presence of high dielectric material such as AC. Authors also observed temperatures up to $1200{ }^{\circ} \mathrm{C}$ for dry AC if treated at the same operating conditions. A maximum water temperature of $103{ }^{\circ} \mathrm{C}$ was also found when MW heating was used for wastewater treatment (Lin et al., 2009; Zalat and Elsayed, 2013). Therefore, obtained results highlight the possibility of successfully and simultaneously remediating both solid and water aquifer phases.

In practical use, the cost-effectiveness of the remedial treatment is a very important concern. Based on the experimental results, a preliminary energy requirement and cost assessment were performed as a function of the condition $(P, t)$ investigated. Specifically, due to the lack of specific information on the in situ MW applicability, achievable only by means of further dedicated studies and their preponderance, only energy costs were considered for the elaboration. Specifically, an electricity cost for industrial consumers of $0.120 € \mathrm{k}^{-1} \mathrm{~W}^{-1} \mathrm{~h}^{-1}$ (Eurostat, 2015) was considered. Elaborations showed specific energy costs in the range $2.6-96 €$ ton $^{-3}$ depending on the power and the treatment time used (Table 6). Therefore, a maximum cost of $96 € \operatorname{ton}^{-3}$ is required to reach a diesel removal of 88 or $80 \%$ in $1 \mathrm{~h}$ from solid or water phase, respectively. Therefore, overall, energy requirement and costs are 
significantly lower than those required for treating diesel-contaminated soils, for which energy costs could rise up to about $160 € \operatorname{ton}^{-3}$ (Falciglia et al., 2014, 2015b).

\subsection{Comparison to other literature findings}

High diesel removal efficiencies observed for MW heating remediation are hardly achievable in such a short time using other in situ biological or chemical treatments. Hess et al. (1996), simulating an in situ bioremediation of aquifers contaminated with diesel based on the infiltration of groundwater supplemented with oxidants (e.g. $\mathrm{O}_{2}, \mathrm{NO}^{3-}$ ) and nutrients, reported a removal of contaminant as nalkanes $\left(\mathrm{C}_{11}-\mathrm{C}_{26}\right)$ after a treatment of 96 days ranging from 53 to $86 \%$ depending on the zone of the reactor used for the experiments. However, removal values drop down to about $20 \%$ when the heaviest hydrocarbon fractions were considered. Results from a study on the bio-remediation of a diesel fuel contaminated aquifer in Switzerland treated by injecting aerated groundwater supplemented with $\mathrm{KNO}_{3}$ and $\mathrm{NH}_{4} \mathrm{H}_{2} \mathrm{PO}_{4}$ were reported by Hunkeler et al. (2002). Authors showed that the total dissolved inorganic carbon production rate in the aquifer decreased within 2 years to about $25 \%$ of that during engineered in situ bioremediation. Van Stempvoort et al. (2002) studied the enhanced solubility of petroleum-derived compounds in humic acid solutions to treat a diesel polluted-aquifer with in situ flushing technology. Experiments were conducted using a contaminated model sand aquifer flushed with water and humic acid over a period of 5 years. Their results showed that during aqueous transport, biodegradation of the BTEX and PAHs occurred, limiting the lateral and longitudinal extent of the diesel contaminant plume in the model aquifer. Lee et al. (2005) reported results from a pilotscale study aimed at investigating the effect of a surfactant-enhanced in situ flushing treatment on the removal of TPH from soil and groundwater contaminated with diesel fuel. Authors observed a TPH $\left(\mathrm{C}_{8}-\mathrm{C}_{40}\right)$ removal of about $88 \%$ flushing a sorbitan monoleate solution for approximately 3 months. The overall effectiveness of the investigated treatment is further highlighted by comparing obtained results from diesel removal from solid phase with experimental findings on a diesel-polluted soil treatment. Contaminant removals observed in such a short remediation time are hardly achievable by other treatments, especially if they are bioprocess-based. In this case, diesel removal values not higher than about $80 \%$ and remediation times of up to 300 days were observed by several authors (Fernández 
et al., 2011; Łebkowska et al., 2011; Li et al., 2007; Liu et al., 2013). More recently, Szulc et al. (2014), in a study focused on assessing the influence of bioaugmentation and the addition of rhamnolipids on contaminant biodegradation during field studies of extended length (365 days), reported a maximum diesel removal of about $85 \%$. Mena et al. (2015) reported bench-scale results on coupled electrokinetic soil flushing (EKSF) and bioremediation through biological permeable reactive barriers (Bio-PRBs) for remediation of diesel-contaminated soils. Authors showed a contaminant removal of $30 \%$ in a 14 day-treatment time. De Rosa et al. (2015) showed a diesel removal from soil using microfoams of biological and chemical surfactants of about $45 \%$. The chemical treatment application could likewise lead to a low diesel removal. Do et al. (2009) showed that a peroxymonosulphate/cobalt based chemical oxidation of a soil contaminated at $5000 \mathrm{mg} \mathrm{kg}^{-1}$ was characterized by a maximum degradation of $47 \%$.

In economic terms, it is clear that, even if energy costs are predominant, those obtained in this work allow for a mere preliminary comparison with other technologies' costs. A preliminary comparison is, in any case, useful for realising the cost-effective potentiality of the investigated treatment. More detailed costs can be assessable only by means of the elaboration of results from further scaling-up or in situ investigations.

Specifically, for in situ flushing remediation, Khan et al. (2004) reported treatment costs in the range $30-296 € \mathrm{~m}^{-3}$ depending on the type and the concentration of the contaminants. Based on a report of the Federal Remediation Technologies Roundtable (FRTR) elaborated in 2006, airsparging is characterized by a cost of $76 € \mathrm{~m}^{-3}$, while, in a report of Remediation Technology Costs in the UK \& Europe (2001-2005), Summersgill (2006) showed air-sparging costs in the range $11-360 € \mathrm{~m}^{-3}$ (average $91 € \mathrm{~m}^{-3}$ ). On the other hand, techniques, as in situ chemical oxidation (ISCO), characterised by high performance in terms of rapidity of removal kinetics and contaminant removal comparable to those of MW heating, present costs generally higher than those required for the MW one. Recently, Innocenti et al (2014), investigating a pilot-scale ISCO treatment of a MtBE contaminated site (groundwater contamination with concentrations up to $3000 \mu \mathrm{g} \mathrm{L}^{-1} \mathrm{TPHs}$ and $4000 \mu \mathrm{g} \mathrm{L}^{-1} \mathrm{MtBE}$ ) 
using a Fenton-like process, reported THP-removal from groundwater lower than $90 \%$ and unit costs, considering only the reagents and the construction of wells, equal to $195 € \mathrm{~m}^{-3}$.

Based on the above considerations, MW heating treatment has the potentiality to provide more extensive, rapid, and cost-effective treatment than physical, chemical or biological techniques, representing a suitable alternative to remediate diesel-polluted aquifer.

\section{Conclusions}

The following conclusions have been drawn based on lab-scale experimental results and discussion:

- In diesel-contaminated aquifer MW remediation, the operating power applied significantly influences the final temperature reachable during heating and, consequently, the contaminant removal kinetics characterizing both the solid and the water phases. For the investigated power of 160 and $350 \mathrm{~W}$, an aquifer temperature of 102 or $110{ }^{\circ} \mathrm{C}$ was observed, respectively, at the end of the treatment whereas a maximum temperature of about $120{ }^{\circ} \mathrm{C}$ was reached at $500 \mathrm{~W}$ irradiation. Observed temperature values depended on the simultaneous irradiation of aquifer grains and groundwater. In this case, solid phases act as "hot spots" but their temperature effects are limited by the presence of interstitial water, which, despite being the best MW (absorbing at $2.45 \mathrm{GHz}$ frequency), limits the overall temperature of the aquifer system due to the maximum temperature it can reach before evaporation.

- A minimal residual diesel concentration adsorbed on the solid phase of about $100 \mathrm{mg} \mathrm{kg}^{-1}$ was achieved by applying a power of $500 \mathrm{~W}$ for a treatment time of $60 \mathrm{~min}$, whereas the contaminant concentration was only halved (about $400 \mathrm{mg} \mathrm{kg}^{-1}$ ) by using a power of $160 \mathrm{~W}$. In the case of the water phase treatment, the application of a $500 \mathrm{~W}$ power for treatment times higher than 5 min resulted in a significant reduction of contaminants in water from 575 to about $100 \mathrm{mg} \mathrm{L}^{-1}$. Overall, MW heating resulted in preferential effects of the thermal treatment on the removal of different TPH molecular weight fractions and their moving between the two phases. In addition, a consideration of the maximum temperature values observed during the treatment reveals that evaporation-stripping phenomena plays a major role in final 
contaminant removal processes. Specifically, the progressive evaporation of the lightest TPH fractions acting as solvent produced a solubilisation/extraction of the heaviest fractions that were removed, this also due to the physical stripping phenomena. In addition, the presence of a vapour stream leads to an increase of vapour pressure resulting in a reduction of the temperature needed for the contaminant desorption and consequently in an increase in removal efficiency.

- The nonlinear exponential decay equation shows an excellent fit $\left(\mathrm{r}^{2}>0.993\right)$ with the experimental data for the solid phase residual concentration at all powers investigated. All kinetic data obtained for the different experimental conditions could represent a valuable tool in calculating the residual contaminant level at any given initial contaminant concentration and consequently in assessing the variation of energy consumption and energy costs, as well as in identifying the optimal operating conditions required to reach specific targeted levels of remediation. Obtained results can serve as a foundation for further scaling-up MW process investigations needed in order to define the real scale applicability of the treatment and related costs.

- A maximum diesel removal of 88 or $80 \%$ was observed for the MW treatment of the solid or water phase, respectively, jointly with the limited unit costs (maximum $96 €$ ton $^{-1}$ ) required, highlighting the possibility of successfully and simultaneously remediating both aquifer phases. Consequently, MW treatment could be a better choice for the rapid remediation of diesel-contaminated aquifers.

\section{Acknowledgements}

The authors gratefully acknowledge support from Electric Field Laboratory of Physic and Astronomy Department (supervisor prof. S. Romano) of the University of Catania.

\section{References}


Al-harahsheh, M., Kingman, S., Al-Makhadmah, L., Hamilton, I.E., 2014. Microwave treatment of electric arc furnace dust with PVC: Dielectric characterization and pyrolysis-leaching. J. Hazard. Mater. 274, 87-97. doi:10.1016/j.jhazmat.2014.03.019

Barba, A.A., Acierno, D., D’Amore, M., 2012. Use of microwaves for in-situ removal of pollutant compounds from solid matrices. J. Hazard. Mater. 207-208, 128-135. doi:10.1016/j.jhazmat.2011.07.123

Benedetto, A., Calvi, A., 2013. A pilot study on microwave heating for production and recycling of road pavement materials. Constr. Build. Mater. 44, 351-359. doi:10.1016/j.conbuildmat.2013.02.082

Bortone, I., Di Nardo, A., Di Natale, M., Erto, A., Musmarra, D., Santonastaso, G.F., 2013. Remediation of an aquifer polluted with dissolved tetrachloroethylene by an array of wells filled with activated carbon. J. Hazard. Mater. 260, 914-920. doi:10.1016/j.jhazmat.2013.06.050

Buttress, A.J., Binner, E., Yi, C., Palade, P., Robinson, J.P., Kingman, S.W., 2016. Development and evaluation of a continuous microwave processing system for hydrocarbon removal from solids. Chem. Eng. J. 283, 215-222.

Careghini, A., Saponaro, S., Sezenna, E., Daghio, M., Franzetti, A., Gandolfi, I., (2015). Lab-scale tests and numerical simulations for in situ treatment of polluted groundwater. J. Hazard. Mater. 287, 162-170. doi:10.1016/j.jhazmat.2015.01.028

Chien, Y., (2012). Field study of in situ remediation of petroleum hydrocarbon contaminated soil on site using microwave energy. J. Hazard. Mater. 199-200, 457-461.

Diprose, M.F., 2001. Some considerations when using a microwave oven as a laboratory research tool. Plant and Soil 229, 271-280.

Da Rosa, C.F.C., Freire, D.M.G., Ferraz, H.C., 2015. Biosurfactant microfoam: Application in the removal of pollutants from soil. J. Environ. Chem. Eng. 3, 89-94. doi:10.1016/j.jece.2014.12.008

Do, S.H., Jo, J.H., Jo, Y.H., Lee, H.K., Kong, S.H., 2009. Application of a peroxymonosulfate/cobalt (PMS/Co(II)) system to treat diesel-contaminated soil. Chemosphere 77, 1127-1131. doi:10.1016/j.chemosphere.2009.08.061

Falciglia, P.P., Giustra, M.G., Vagliasindi, F.G.A., 2011a. Remediation By Thermal Desorption of Diesel-Contaminated Soils. Chem. Ecol. 27, 119-130. doi:10.1080/02757540.2010.534087

Falciglia, P.P., Giustra, M.G., Vagliasindi, F.G.A., 2011b. Low-temperature thermal desorption of diesel polluted soil: Influence of temperature and soil texture on contaminant removal kinetics. J. Hazard. Mater. 185, 392-400. doi:10.1016/j.jhazmat.2010.09.046

Falciglia, P.P., Urso, G., Vagliasindi, F.G.A., 2013. Microwave heating remediation of soils contaminated with diesel fuel. J. Soils Sediments 13, 1396-1407. doi:10.1007/s11368-013-0727$\mathrm{X}$

Falciglia, P.P., Vagliasindi, F.G.A., 2014. Remediation of hydrocarbon-contaminated soils by ex situ microwave treatment: technical, energy and economic considerations. Environ. Technol. 35-18, 2280-2288. doi: 10.1080/09593330.2014.902109 
Falciglia, P.P., Vagliasindi, F.G.A., 2015a. Remediation of hydrocarbon polluted soils using $2.45 \mathrm{GHz}$ frequency-heating: Influence of operating power and soil texture on soil temperature profiles and contaminant removal kinetics. J. Geochemical Explor. 151, 66-73. doi:10.1016/j.gexplo.2015.01.007

Falciglia, P.P., Vagliasindi, F.G.A., 2015b. Techno-economic analysis of hydrocarbon-polluted soil treatment by using ex situ microwave heating: influence of soil texture and soil moisture on electric field penetration, operating conditions and energy costs. J. Soils Sediments. doi: 10.1007/s11368-015-1130-6

Fan, X., He, L., Lu, H.W., Li, J., 2014. Environmental- and health-risk-induced remediation design for benzene-contaminated groundwater under parameter uncertainty: A case study in Western Canada. Chemosphere 111, 604-612. doi:10.1016/j.chemosphere.2014.04.082

Fernández, M.D., Pro, J., Alonso, C., Aragonese, P., Tarazona, J.V., 2011. Terrestrial microcosms in a feasibility study on the remediation of diesel-contaminated soils. Ecotoxicol. Environ. Saf. 74, 2133-2140. doi:10.1016/j.ecoenv.2011.08.009

Folch, A., Vilaplana, M., Amado, L., Vicent, T., Caminal, G., 2013. Fungal permeable reactive barrier to remediate groundwater in an artificial aquifer. J. Hazard. Mater. 262, 554-560. doi:10.1016/j.jhazmat.2013.09.004

FRTR, 2006. Airsparging. Federal Remediation Technologies Roundtable. USEPA, 401 M. street S.W., Washington, DC.

Garoma, T., Gurol, M.D., Osibodu, O., Thotakura, L., 2008. Treatment of groundwater contaminated with gasoline components by an ozone/UV process. Chemosphere 73, 825-831. doi:10.1016/j.chemosphere.2008.06.061

Gomes, H.I., Dias-Ferreira, C., Ribeiro, A.B., 2013. Overview of in situ and ex situ remediation technologies for PCB-contaminated soils and sediments and obstacles for full-scale application. Sci. Total Environ. 445-446, 237-260. doi:10.1016/j.scitotenv.2012.11.098

Hess, a., Höhener, P., Hunkeler, D., Zeyer, J., 1996. Bioremediation of a diesel fuel contaminated aquifer: Simulation studies in laboratory aquifer columns. J. Contam. Hydrol. 23, 329-345. doi:10.1016/0169-7722(95)00107-7

Huang, G.Y., Zhao, L., Dong, Y.H., Zhang, Q., 2011. Remediation of soils contaminated with polychlorinated biphenyls by microwave-irradiated manganese dioxide. J. Hazard. Mater. 186, 128-132. doi:10.1016/j.jhazmat.2010.10.092

Hunkeler, D., Höhener, P., Zeyer, J., 2002. Engineered and subsequent intrinsic in situ bioremediation of a diesel fuel contaminated aquifer. J. Contam. Hydrol. 59, 231-245. doi:10.1016/S0169$7722(02) 00059-1$

Jagtap, S.S., Woo, S.M., Kim, T.S., Dhiman, S.S., Kim, D., Lee, J.K., 2014. Phytoremediation of diesel-contaminated soil and saccharification of the resulting biomass. Fuel 116, 292-298. doi:10.1016/j.fuel.2013.08.017

Khan, F.I., Husain, T., Hejazi, R., 2004. An overview and analysis of site remediation technologies. J. Environ. Manage. 71, 95-122. doi:10.1016/j.jenvman.2004.02.003 
Kawala, Z., Atamańczuk, T., 1998. Microwave-enhanced thermal decontamination of soil. Environ. Sci. Technol. 32, 2602-2607. doi:10.1021/es980025m

Kim, I., Lee, M., 2012. Pilot scale feasibility study for in-situ chemical oxidation using $\mathrm{H} 2 \mathrm{O} 2$ solution conjugated with biodegradation to remediate a diesel contaminated site. J. Hazard. Mater. 241242, 173-181. doi:10.1016/j.jhazmat.2012.09.022

Łebkowska, M., Zborowska, E., Karwowska, E., Miaśkiewicz-Peska, E., Muszyński, A., Tabernacka, A., Naumczyk, J., Jeczalik, M., 2011. Bioremediation of soil polluted with fuels by sequential multiple injection of native microorganisms: Field-scale processes in Poland. Ecol. Eng. 37, 1895-1900. doi:10.1016/j.ecoleng.2011.06.047

Lee, G.T., Ro, H.M., Lee, S.M., (2007). Effects of triethyl phosphate and nitrate on electrokinetically enhanced biodegradation of diesel in low permeability soils. Environ. Tech. 28-8, 853-860

Lee, M., Kang, H., Do, W., 2005. Application of nonionic surfactant-enhanced in situ flushing to a diesel contaminated site. Water Res. 39, 139-146. doi:10.1016/j.watres.2004.09.012

Li, D., Zhang, Y., Quan, X., Zhao, Y., 2009. Microwave thermal remediation of crude oil contaminated soil enhanced by carbon fiber. J. Environ. Sci. 21, 1290-1295. doi:10.1016/S1001$0742(08) 62417-1$

Li, H., Zhang, Y., Kravchenko, I., Xu, H., Zhang, C.G., 2007. Dynamic changes in microbial activity and community structure during biodegradation of petroleum compounds: A laboratory experiment. J. Environ. Sci. 19, 1003-1013. doi:10.1016/S1001-0742(07)60163-6

Liang, S.H., Kao, C.M., Kuo, Y.C., Chen, K.F., Yang, B.M., 2011. In situ oxidation of petroleumhydrocarbon contaminated groundwater using passive ISCO system. Water Res. 45, 2496-2506. doi:10.1016/j.watres.2011.02.005

Lin, L., Chen, J., Xu, Z., Yuan, S., Cao, M., Liu, H., Lu, X., 2009. Removal of ammonia nitrogen in wastewater by microwave radiation: A pilot-scale study. J. Hazard. Mater. 168, 862-867. doi:10.1016/j.jhazmat.2009.02.113

Lin, L., Yuan, S., Chen, J., Wang, L., Wan, J., Lu, X., 2010. Treatment of chloramphenicolcontaminated soil by microwave radiation. Chemosphere 78, 66-71. doi:10.1016/j.chemosphere.2009.09.054

Liu, P.-W.G., Chang, T.C., Chen, C.-H., Wang, M.-Z., Hsu, H.-W., 2013. Effects of soil organic matter and bacterial community shift on bioremediation of diesel-contaminated soil. Int. Biodeterior. Biodegrad. 85, 1-10. doi:10.1016/j.ibiod.2013.01.010

Liu, X., Yu, G., 2006. Combined effect of microwave and activated carbon on the remediation of polychlorinated biphenyl-contaminated soil. Chemosphere 63, 228-235. doi:10.1016/j.chemosphere.2005.08.030

Mackay, D., Shiu, W.Y., Ma, K.C., Lee, S.C., 2006. Handbook of Physical - Chemical Properties and Environmental Fate for Organic Chemicals. Taylor \& Francis Group, Broken Sound Parkway NW, Suite 300 Boca Raton. 
Mena, E., Ruiz, C., Villaseñor, J., Rodrigo, M. a., Cañizares, P., 2015. Biological permeable reactive barriers coupled with electrokinetic soil flushing for the treatment of diesel-polluted clay soil. J. Hazard. Mater. 283, 131-139. doi:10.1016/j.jhazmat.2014.08.069

Molson, J.W., Frind, E.O., Van Stempvoort, D.R., Lesage, S., 2002. Humic acid enhanced remediation of an emplaced diesel source in groundwater. 2. Numerical model development and application. J. Contam. Hydrol. 54, 277-305. doi:10.1016/S0169-7722(01)00181-4

Oya, S., Valocchi, A.J., 1998. Analytical approximation of biodegradation rate for in situ bioremediation of groundwater under ideal radial flow conditions. J. Contam. Hydrol. 31, 275293. doi:10.1016/S0169-7722(97)00066-1

Pazos, M., Plaza, A., Martín, M, Lobo, M.C., 2012. The impact of electrokinetic treatment on a loamy-sand soil properties. Cem. Eng. J. 183, 231-237. doi: 10.1016/j.cej.2011.12.067

Pereira, M.S., Panisset, C.M.D.Á., Martins, A.L., Sá, C.H.M., De Barrozo, M.A.D.S., Ataíde, C.H., 2014. Microwave treatment of drilled cuttings contaminated by synthetic drilling fluid. Sep. Purif. Technol. 124, 68-73. doi:10.1016/j.seppur.2014.01.011

Quan, X., Zhang, Y., Chen, S., Zhao, Y., Yang, F., 2007. Generation of hydroxyl radical in aqueous solution by microwave energy using activated carbon as catalyst and its potential in removal of persistent organic substances. J. Mol. Catal. A Chem. 263, 216-222. doi:10.1016/j.molcata.2006.08.079

Remya, N., Lin, J.G., 2011. Current status of microwave application in wastewater treatment-A review. Chem. Eng. J. 166, 797-813. doi:10.1016/j.cej.2010.11.100

Robinson, J., Binner, E., Saeid, A., Al-Harahsheh, M., Kingman, S., 2014. Microwave processing of Oil Sands and contribution of clay minerals. Fuel 135, 153-161. doi:10.1016/j.fuel.2014.06.057

Robinson, J.P., Kingman, S.W., Lester, E.H., Yi, C., 2012. Microwave remediation of hydrocarboncontaminated soils - Scale-up using batch reactors. Sep. Purif. Technol. 96, 12-19. doi:10.1016/j.seppur.2012.05.020

Robinson, J.P., Kingman, S.W., Snape, C.E., Shang, H., Barranco, R., Saeid, A., 2009. Separation of polyaromatic hydrocarbons from contaminated soils using microwave heating. Sep. Purif. Technol. 69, 249-254. doi:10.1016/j.seppur.2009.07.024

Silva-Castro, G.A., Rodelas, B., Perucha, C., Laguna, J., González-López, J., Calvo, C., 2013. Bioremediation of diesel-polluted soil using biostimulation as post-treatment after oxidation with Fenton-like reagents: Assays in a pilot plant. Sci. Total Environ. 445-446, 347-355. doi:10.1016/j.scitotenv.2012.12.081

Summersgill M., 2006. Remediation technology costs in the UK \& Europe; drivers and changes from 2001 to 2005. In: Telford T, editor. Proceedings of the 5th International GeoEnviro Conference, June 2006, Cardiff.

Szulc, A., Ambrozewicz, D., Sydow, M., Ławniczak, Ł., Piotrowska-Cyplik, A., Marecik, R., Chrzanowski, Ł., 2014. The influence of bioaugmentation and biosurfactant addition on bioremediation efficiency of diesel-oil contaminated soil: Feasibility during field studies. J. Environ. Manage. 132, 121-128. doi:10.1016/j.jenvman.2013.11.006 
Tatàno, F., Felici, F., Mangani, F., 2013. Lab-Scale Treatability Tests for the Thermal Desorption of Hydrocarbon-Contaminated Soils. Soil Sediment Contam. An Int. J. 22, 433-456. doi: $10.1080 / 15320383.2013 .721814$

Tyagi, V.K., Lo, S.L., 2013. Microwave irradiation: A sustainable way for sludge treatment and resource recovery. Renew. Sustain. Energy Rev. 18, 288-305. doi:10.1016/j.rser.2012.10.032

Van Stempvoort, D.R., 2002. Humic acid enhanced remediation of an emplaced diesel source in groundwater. 1. Laboratory-based pilot scale test. J. Contam. Hydrol. 54, 249-276.

Xin, B.P., Wu, C.H., Wu, C.H., Lin, C.W., 2013. Bioaugmented remediation of high concentration BTEX-contaminated groundwater by permeable reactive barrier with immobilized bead. J. Hazard. Mater. 244-245, 765-772. doi:10.1016/j.jhazmat.2012.11.007

Yuan, S., Tian, M., Lu, X., 2006. Microwave remediation of soil contaminated with hexachlorobenzene. J. Hazard. Mater. 137, 878-885. doi:10.1016/j.jhazmat.2006.03.005

Zalat, O.A., Elsayed, M.A., 2013. A study on microwave removal of pyridine from wastewater. J. Environ. Chem. Eng. 1, 137-143. doi:10.1016/j.jece.2013.04.010 


\section{Figure legends}

Figure 1. Schematic of bench-scale microwave apparatus.

Figure 2. Temperature $(\mathrm{T})$ profiles of aquifer with time $(\mathrm{t})$ during MW radiation at investigated power (P) series of 160 , 350 , and $500 \mathrm{~W}$.

Figure 3. Residual diesel concentration (C) on solid phase with time and power low kinetic model curves at powers of 160,350 , and $500 \mathrm{~W}$.

Figure 4. Rate of dacay $(\mathrm{k})$ as a function of treatment power $(\mathrm{P})$.

Figure 5. Residual diesel concentration $(\mathrm{C})$ in water phase with time at powers of 160,350 , and $500 \mathrm{~W}$.

Figure 6. Diesel removal (R) from solid phase with time at powers of 160, 350, and $500 \mathrm{~W}$.

Figure 7. Diesel removal (R) from water phase with time at powers of 160, 350, and $500 \mathrm{~W}$. 


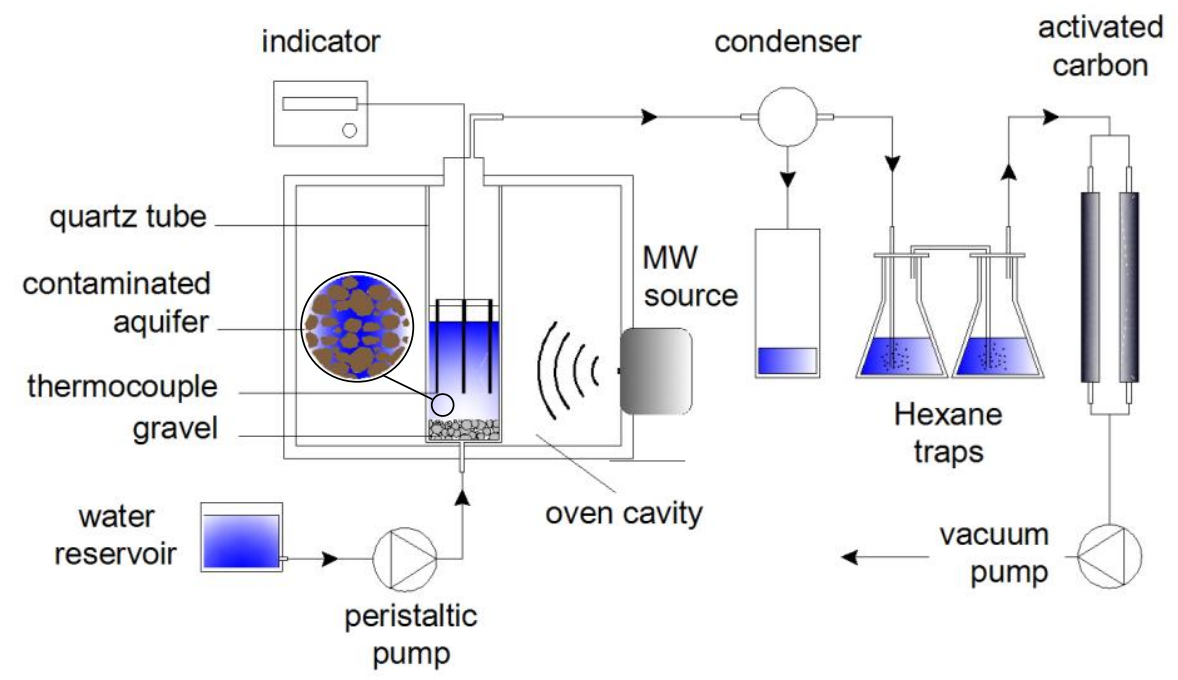

Figure 1. Schematic of bench-scale microwave apparatus.

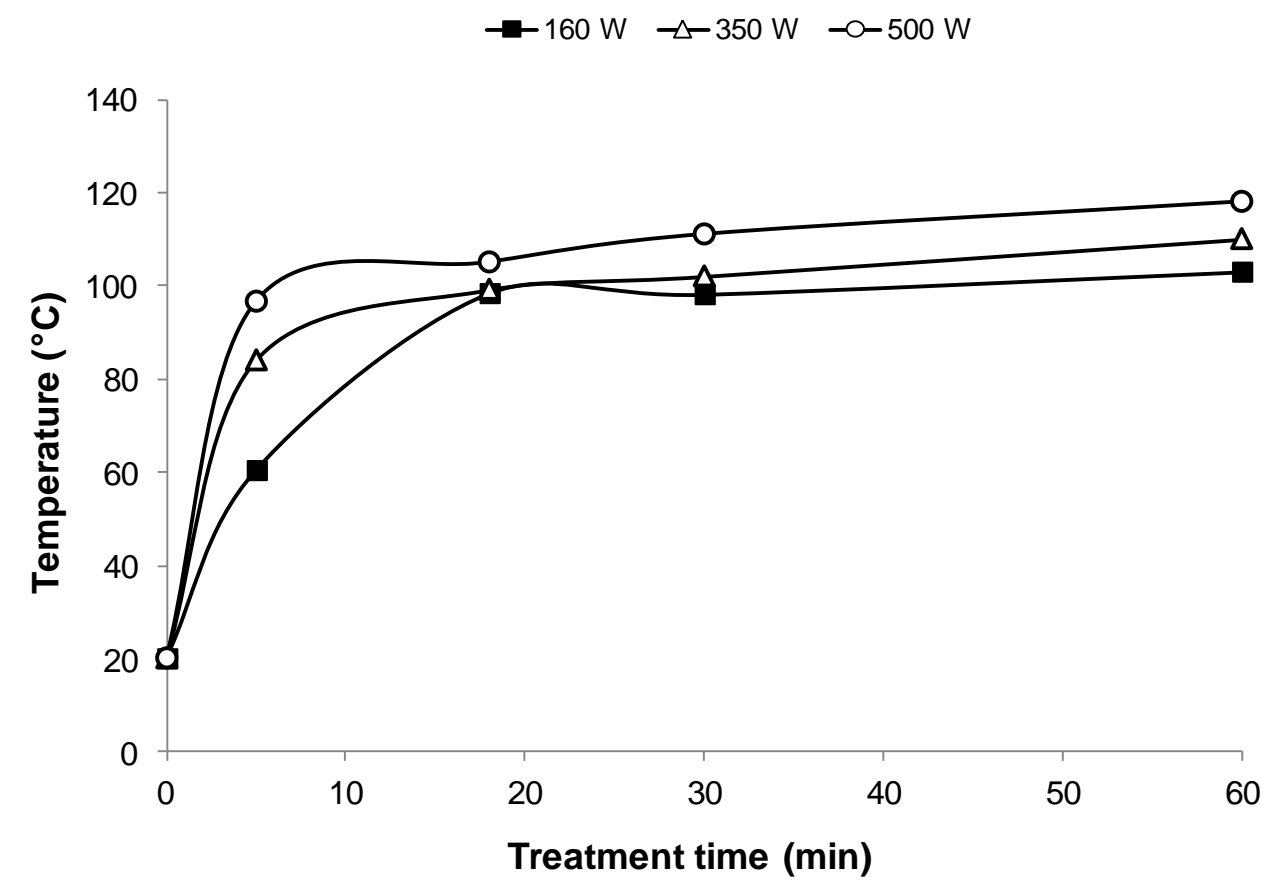

Figure 2. Temperature $(T)$ profiles of aquifer with time $(t)$ during MW radiation at investigated power $(P)$ series of 160 , 350 , and $500 \mathrm{~W}$. 


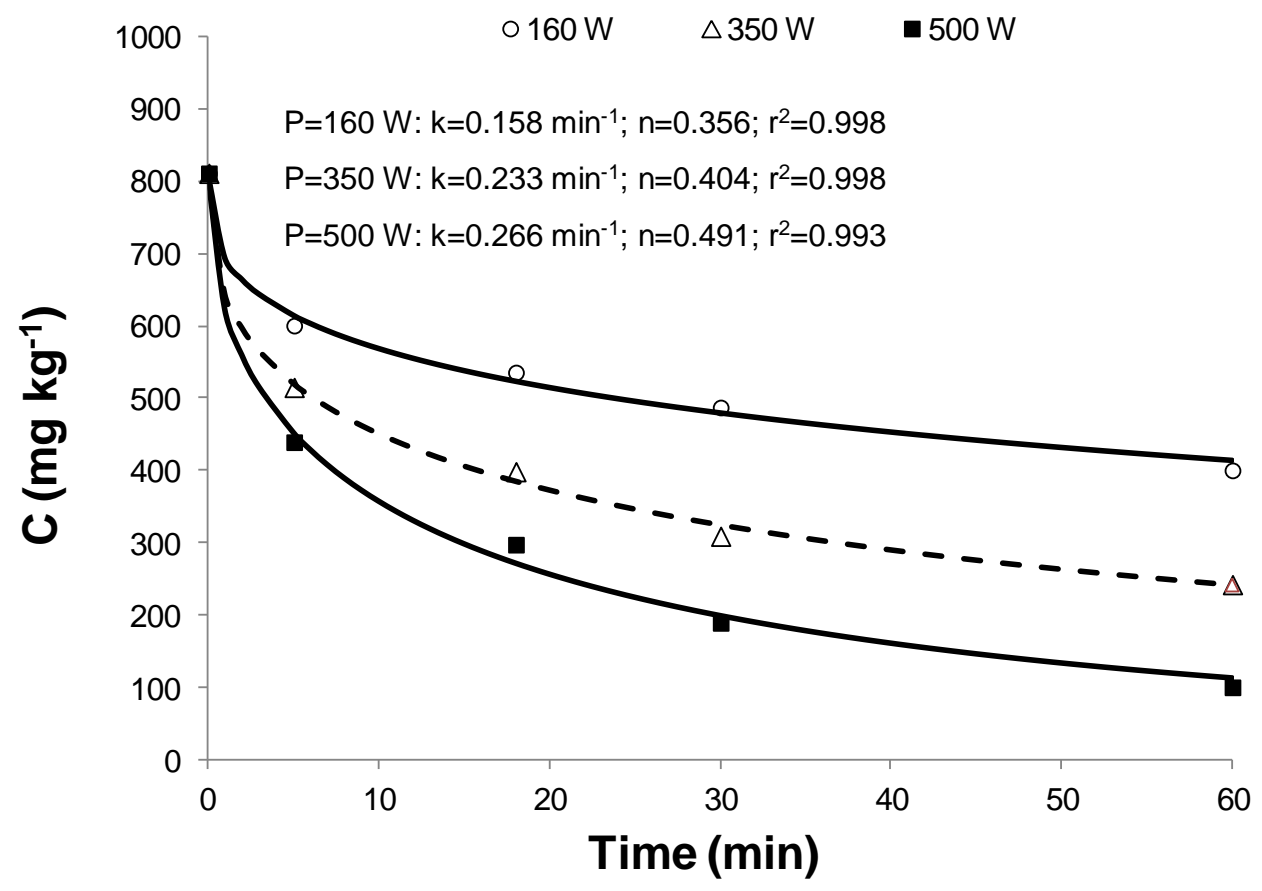

Figure 3. Residual diesel concentration $(C)$ on solid phase with time and power low kinetic model curves at powers of 160,350 , and $500 \mathrm{~W}$.

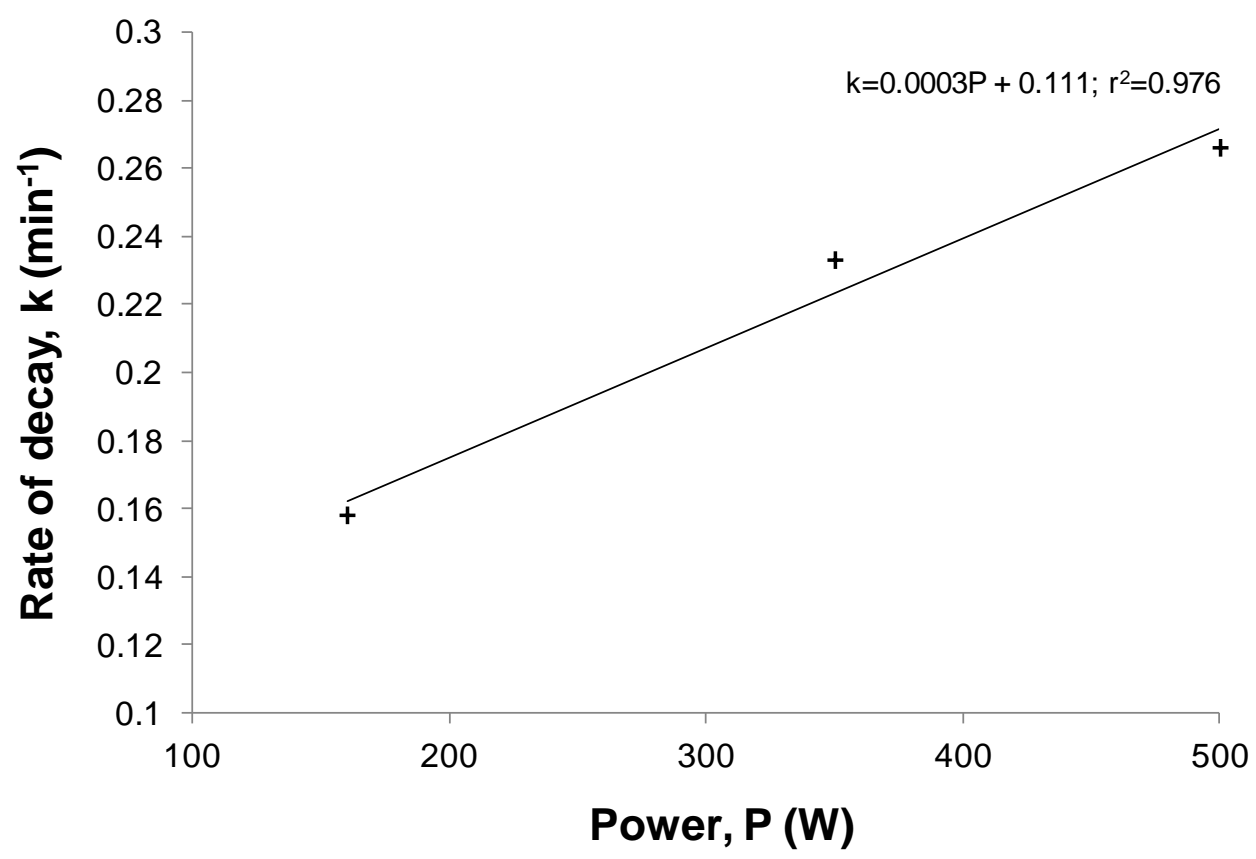

Figure 4. Rate of dacay $(k)$ as a function of treatment power $(P)$. 


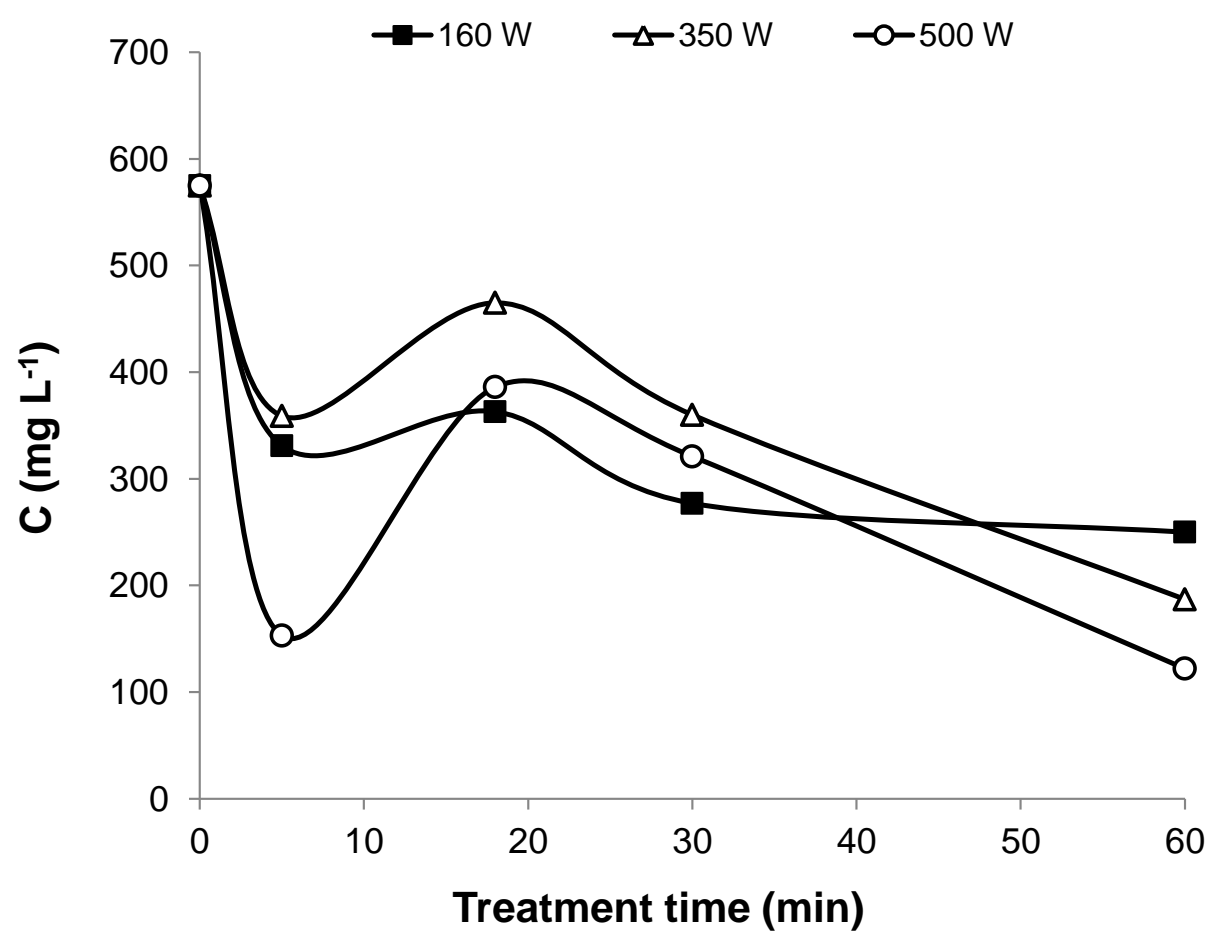

Figure 5. Residual diesel concentration $(C)$ in water phase with time at powers of 160,350 , and $500 \mathrm{~W}$.

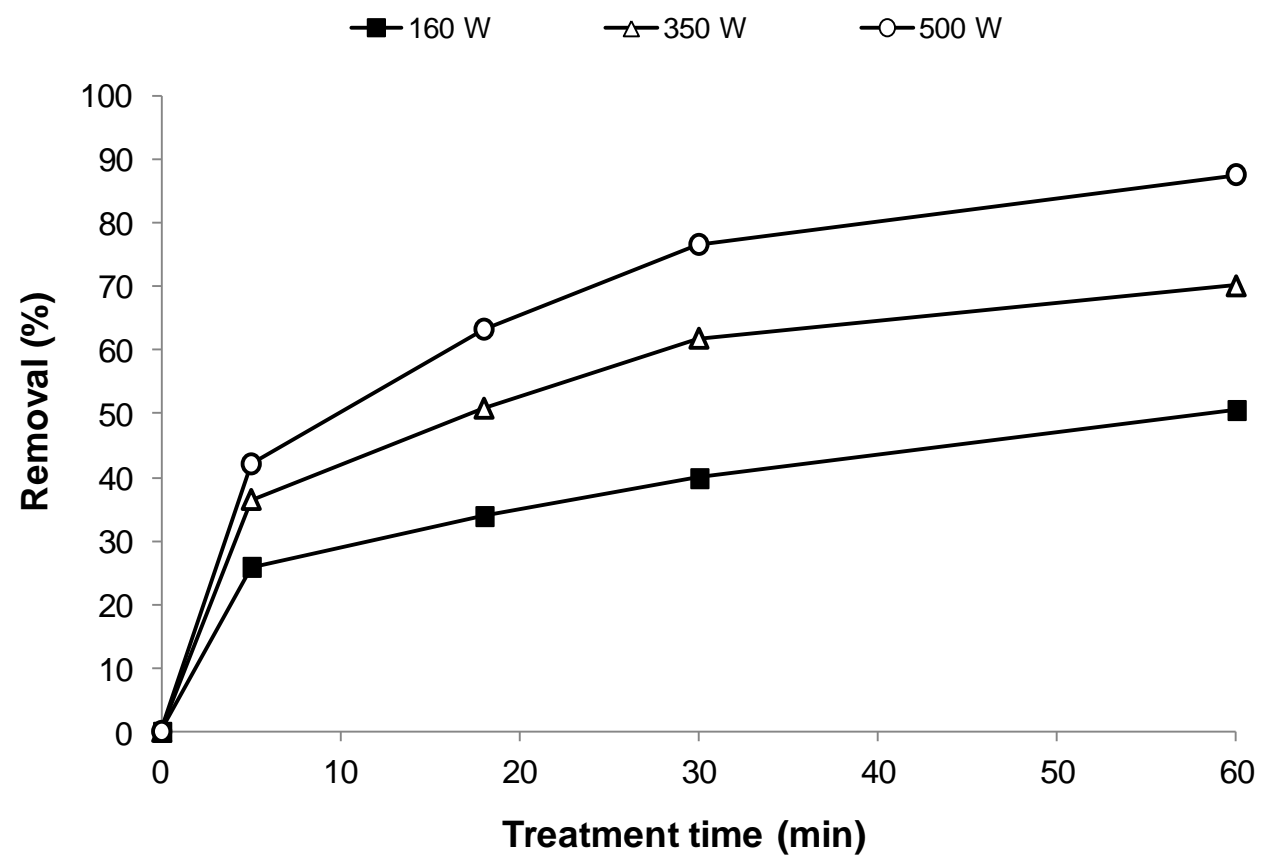

Figure 6. Diesel removal $(R)$ from solid phase with time at powers of 160, 350, and $500 \mathrm{~W}$. 


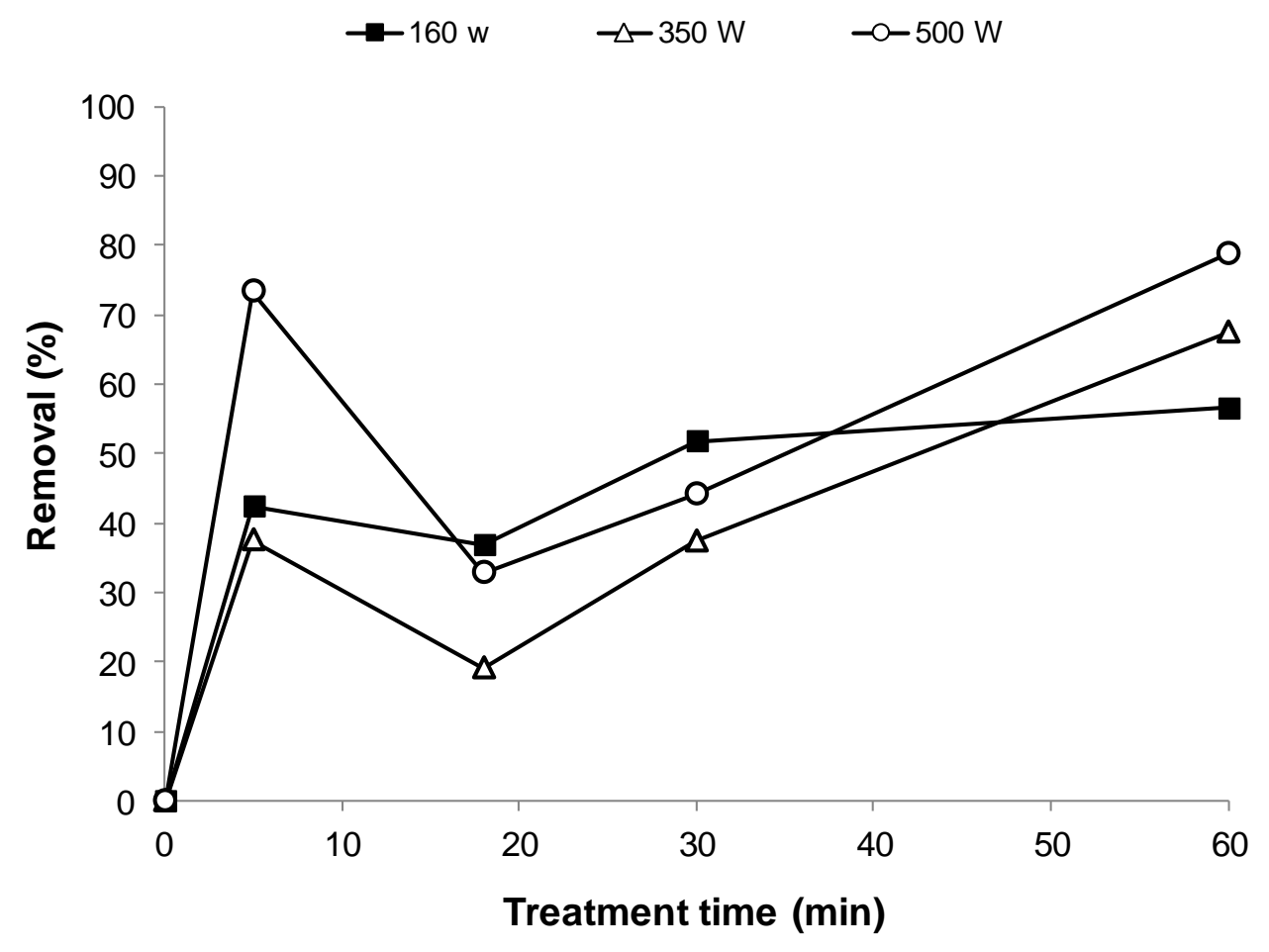

Figure 7. Diesel removal $(R)$ from water phase with time at powers of 160, 350, and $500 \mathrm{~W}$. 


\section{Table legends}

Table 1. Properties and characteristics of selected medium sand.

Table 2. Flow rate values flushed through the system as a function of time $(t)$ and irradiation power (P).

Table 3. Distribution of diesel $\left(C_{0}\right)$ on solid and water phases as TPH fractions after the contamination procedure.

Table 4. Distribution of residual diesel $(C)$ adsorbed on solid phase as TPH fractions after the MW irradiation at power of 160, 350 and $500 \mathrm{~W}$.

Table 5. Distribution of residual diesel $(C)$ in water phase as TPH fractions after the MW irradiation at power of 160, 350 and $500 \mathrm{~W}$.

Table 6. Energy requirement and energy costs for the investigated treatments. 
Table 1. Properties and characteristics of selected medium sand.

\begin{tabular}{|c|c|c|}
\hline Parameter & Method & Value \\
\hline Mineral & & Silica sand \\
\hline Texture $(\mu \mathrm{m})$ & & $50-1000$ \\
\hline $\mathrm{pH}$ & ASTM D4972-13 ${ }^{(1)}$ & 8.73 \\
\hline Bulk density $\left(\mathrm{g} \mathrm{cm}^{-3}\right)$ & ASTM D7263-09(2) & 1.42 \\
\hline Specific surface area $\left(\mathrm{m}^{2} \mathrm{~g}^{-1}\right)$ & $\mathrm{EGME}^{(3)}$ & 2.11 \\
\hline Organic matter $\left(\mathrm{g} \mathrm{kg}^{-1}\right)$ & UV-VIS ${ }^{(4)}$ & 0.88 \\
\hline Specific heat capacity $\left(\mathrm{KJ} \mathrm{kg}^{-1}{ }^{\circ} \mathrm{C}^{-1}\right)$ & ASTM E1269-11 (5) & 932 \\
\hline Dielectric constant $\left(\varepsilon^{\prime}\right)$ & cavity perturbation $^{(6)}$ & 7.21 \\
\hline Loss factor $\left(\varepsilon^{\prime \prime}\right)$ & cavity perturbation $^{(6)}$ & 0.78 \\
\hline
\end{tabular}

(1) ASTM D4972-13. Standard Test Method for $\mathrm{pH}$ of Soils.

(2) ASTM D7263-09. Standard Test Methods for Laboratory Determination of Density (Unit Weight) of Soil Specimens.

(3) Simplified Ethylene Glycol Monoethyl Ether (EGME) procedure for assessment of soil surface area (Cihacek and Bremner, 1979).

(4) UV-VIS Method - Test procedure for determining organic matter content in soils (Harvey et al., 2010).

(5) ASTM E1269-11. Standard Test Method for Determining Specific Heat Capacity by Differential Scanning Calorimetry.

(6) Cavity perturbation method for dielectric properties measurements (Sheen, 2005).

Table 2. Flow rate values flushed through the system as a function of time $(t)$ and irradiation power (P).

\begin{tabular}{ccccc}
\hline \multicolumn{4}{c}{ Flow rate $\left(\mathrm{mL} \mathrm{min}^{-1}\right)$} \\
\hline Power $(\mathrm{W})$ & $5 \mathrm{~min}$ & $18 \mathrm{~min}$ & $30 \mathrm{~min}$ & $60 \mathrm{~min}$ \\
\hline 160 & 1.0 & 1.8 & 1.9 & 1.9 \\
350 & 1.8 & 5.9 & 6.1 & 6.1 \\
500 & 3.2 & 8.9 & 8.6 & 8.7 \\
\hline
\end{tabular}

Table 3. Distribution of diesel $\left(C_{0}\right)$ on solid and water phases as TPH fractions after the contamination procedure.

\begin{tabular}{|c|c|c|c|c|c|c|c|c|c|c|}
\hline $\begin{array}{c}\text { TPH } \\
\text { fraction }\end{array}$ & \multicolumn{2}{|c|}{$\mathrm{C}_{12}-\mathrm{C}_{20}$} & \multicolumn{2}{|c|}{$\mathrm{C}_{20}-\mathrm{C}_{30}$} & \multicolumn{2}{|c|}{$\mathrm{C}_{30}-\mathrm{C}_{40}$} & \multicolumn{2}{|c|}{$\mathrm{C}_{40}-\mathrm{C}_{50}$} & \multicolumn{2}{|c|}{$\begin{array}{c}\text { Total } \\
\mathrm{C}_{12}-\mathrm{C}_{50}\end{array}$} \\
\hline \multirow{2}{*}{ Grains (solid) } & $\mathrm{mg} \mathrm{kg}^{-1}$ & $\%$ & $\mathrm{mg} \mathrm{kg}^{-1}$ & $\%$ & $\mathrm{mg} \mathrm{kg}^{-1}$ & $\%$ & $\mathrm{mg} \mathrm{kg}^{-1}$ & $\%$ & $\mathrm{mg} \mathrm{kg}^{-1}$ & $\%$ \\
\hline & 502.5 & 61.9 & 224.2 & 27.6 & 51.1 & 6.3 & 34.0 & 4.2 & 811.8 & 100.0 \\
\hline \multirow{2}{*}{ Water } & $\mathrm{mg} \mathrm{L}^{-1}$ & $\%$ & $\mathrm{mg} \mathrm{L}^{-1}$ & $\%$ & $\mathrm{mg} \mathrm{L}^{-1}$ & $\%$ & $\mathrm{mg} \mathrm{L}^{-1}$ & $\%$ & $\mathrm{mg} \mathrm{mL}^{-1}$ & $\%$ \\
\hline & 422.9 & 73.6 & 136.9 & 23.8 & 15.0 & 2.6 & 0.0 & 0.0 & 575.0 & 100.0 \\
\hline
\end{tabular}

Table 4. Distribution of residual diesel $(C)$ adsorbed on solid phase as TPH fractions after the MW irradiation at power of 160,350 and $500 \mathrm{~W}$.

\begin{tabular}{|c|c|c|c|c|c|c|c|c|c|c|c|c|c|}
\hline \multirow{2}{*}{$\begin{array}{l}\text { Power } \\
\text { (W) }\end{array}$} & \multirow{2}{*}{$\begin{array}{l}\text { Time } \\
(\mathrm{min})\end{array}$} & \multicolumn{3}{|c|}{$\mathrm{C}_{12}-\mathrm{C}_{20}$} & \multicolumn{3}{|c|}{$\mathrm{C}_{20}-\mathrm{C}_{30}$} & \multicolumn{3}{|c|}{$\mathrm{C}_{30}-\mathrm{C}_{40}$} & \multicolumn{3}{|c|}{$\mathrm{C}_{40}-\mathrm{C}_{50}$} \\
\hline & & $\begin{array}{c}\mathrm{C} \\
\left(\mathrm{mg} \mathrm{kg}^{-1}\right)\end{array}$ & $\begin{array}{c}\mathrm{C} \\
(\%) \\
\end{array}$ & $\begin{array}{c}\mathrm{R} \\
(\%)\end{array}$ & $\begin{array}{c}\mathrm{C} \\
\left(\mathrm{mg} \mathrm{kg}^{-1}\right)\end{array}$ & $\begin{array}{c}\mathrm{C} \\
(\%) \\
\end{array}$ & $\begin{array}{c}\mathrm{R} \\
(\%)\end{array}$ & $\begin{array}{c}\mathrm{C} \\
\left(\mathrm{mg} \mathrm{kg}^{-1}\right)\end{array}$ & $\begin{array}{c}\mathrm{C} \\
(\%)\end{array}$ & $\begin{array}{c}\mathrm{R} \\
(\%)\end{array}$ & $\begin{array}{c}\mathrm{C} \\
\left(\mathrm{mg} \mathrm{kg}^{-1}\right)\end{array}$ & $\begin{array}{c}\mathrm{C} \\
(\%)\end{array}$ & $\begin{array}{c}\mathrm{R} \\
(\%)\end{array}$ \\
\hline 160 & 5 & 460.3 & 76.6 & 8.4 & 139.2 & 23.2 & 37.9 & 0.9 & 0.1 & 98.2 & 0.0 & 0.0 & 100.0 \\
\hline 160 & 18 & 403.2 & 75.2 & 19.8 & 132.0 & 24.6 & 41.1 & 0.7 & 0.1 & 98.7 & 0.0 & 0.0 & 100.0 \\
\hline 160 & 30 & 362.0 & 74.2 & 28.0 & 125.0 & 25.6 & 44.3 & 1.0 & 0.2 & 98.0 & 0.0 & 0.0 & 100.0 \\
\hline 160 & 60 & 357.2 & 73.2 & 28.9 & 130.8 & 26.8 & 41.7 & 0.0 & 0.0 & 100.0 & 0.0 & 0.0 & 100.0 \\
\hline 350 & 5 & 388.5 & 75.3 & 22.7 & 126.2 & 24.5 & 43.7 & 0.6 & 0.1 & 98.9 & 0.0 & 0.0 & 100.0 \\
\hline 350 & 18 & 293.1 & 73.4 & 41.7 & 106.1 & 26.6 & 52.7 & 0.0 & 0.0 & 100.0 & 0.0 & 0.0 & 100.0 \\
\hline 350 & 30 & 219.6 & 70.9 & 56.3 & 90.3 & 29.1 & 59.7 & 0.0 & 0.0 & 100.0 & 0.0 & 0.0 & 100.0 \\
\hline 350 & 60 & 217.9 & 70.3 & 56.6 & 92.0 & 29.7 & 59.0 & 0.0 & 0.0 & 100.0 & 0.0 & 0.0 & 100.0 \\
\hline 500 & 5 & 346.2 & 73.6 & 31.1 & 124.1 & 26.4 & 44.7 & 0.0 & 0.0 & 100.0 & 0.0 & 0.0 & 100.0 \\
\hline 500 & 18 & 217.8 & 73.0 & 56.7 & 79.8 & 26.8 & 64.4 & 0.0 & 0.0 & 100.0 & 0.0 & 0.0 & 100.0 \\
\hline 500 & 30 & 134.1 & 70.5 & 73.3 & 56.0 & 29.5 & 75.0 & 0.0 & 0.0 & 100.0 & 0.0 & 0.0 & 100.0 \\
\hline 500 & 60 & 130.8 & 68.8 & 74.0 & 59.3 & 31.2 & 73.5 & 0.0 & 0.0 & 100.0 & 0.0 & 0.0 & 100.0 \\
\hline
\end{tabular}


Table 5. Distribution of residual diesel $(C)$ in water phase as TPH fractions after the MW irradiation at power of 160,350 and $500 \mathrm{~W}$.

\begin{tabular}{|c|c|c|c|c|c|c|c|c|c|c|c|c|c|}
\hline \multirow{2}{*}{$\begin{array}{c}\text { Power } \\
\text { (W) }\end{array}$} & \multirow{2}{*}{$\begin{array}{l}\text { Time } \\
(\mathrm{min})\end{array}$} & \multicolumn{3}{|c|}{$\mathrm{C}_{12}-\mathrm{C}_{20}$} & \multicolumn{3}{|c|}{$\mathrm{C}_{20}-\mathrm{C}_{30}$} & \multicolumn{3}{|c|}{$\mathrm{C}_{30}-\mathrm{C}_{40}$} & \multicolumn{3}{|c|}{$\mathrm{C}_{40}-\mathrm{C}_{50}$} \\
\hline & & $\begin{array}{c}\mathrm{C} \\
\left(\mathrm{mg} \mathrm{L}^{-1}\right)\end{array}$ & $\begin{array}{c}\mathrm{C} \\
(\%)\end{array}$ & $\begin{array}{c}\mathrm{R} \\
(\%)\end{array}$ & $\begin{array}{c}\mathrm{C} \\
\left(\mathrm{mg} \mathrm{L}^{-1}\right)\end{array}$ & $\begin{array}{c}\mathrm{C} \\
(\%) \\
\end{array}$ & $\begin{array}{c}\mathrm{R} \\
(\%)\end{array}$ & $\begin{array}{c}\mathrm{C} \\
\left(\mathrm{mg} \mathrm{L}^{-1}\right)\end{array}$ & $\begin{array}{c}\mathrm{C} \\
(\%) \\
\end{array}$ & $\begin{array}{c}\mathrm{R} \\
(\%)\end{array}$ & $\begin{array}{c}\mathrm{C} \\
\left(\mathrm{mg} \mathrm{L}^{-1}\right)\end{array}$ & $\begin{array}{c}\mathrm{C} \\
(\%)\end{array}$ & $\begin{array}{c}\mathrm{R} \\
(\%)\end{array}$ \\
\hline 160 & 5 & 248.5 & 75.1 & 41.2 & 73.2 & 22.1 & 46.5 & 9.3 & 2.8 & 38.0 & 0.0 & 0.0 & 100.0 \\
\hline 160 & 18 & 265.2 & 73.1 & 37.3 & 87.8 & 24.2 & 35.8 & 9.8 & 2.7 & 34.4 & 0.0 & 0.0 & 100.0 \\
\hline 160 & 30 & 202.8 & 73.2 & 52.1 & 71.3 & 25.7 & 47.9 & 2.9 & 1.1 & 80.5 & 0.0 & 0.0 & 100.0 \\
\hline 160 & 60 & 196.9 & 71.1 & 53.4 & 75.6 & 27.3 & 44.7 & 4.4 & 1.6 & 70.4 & 0.0 & 0.0 & 100.0 \\
\hline 350 & 5 & 286.6 & 79.8 & 32.2 & 72.3 & 20.1 & 47.2 & 0.1 & 0.03 & 99.3 & 0.0 & 0.0 & 100.0 \\
\hline 350 & 18 & 347.4 & 74.7 & 17.9 & 103.7 & 22.3 & 24.2 & 14.0 & 3.0 & 6.7 & 0.0 & 0.0 & 100.0 \\
\hline 350 & 30 & 267.5 & 74.3 & 36.8 & 88.3 & 24.5 & 35.5 & 4.3 & 1.2 & 71.1 & 0.0 & 0.0 & 100.0 \\
\hline 350 & 60 & 266.4 & 74.0 & 37.0 & 88.9 & 24.7 & 35.0 & 4.7 & 1.3 & 68.7 & 0.0 & 0.0 & 100.0 \\
\hline 500 & 5 & 117.0 & 76.5 & 72.3 & 35.1 & 22.9 & 74.4 & 0.9 & 0.6 & 94.1 & 0.0 & 0.0 & 100.0 \\
\hline 500 & 18 & 278.3 & 72.1 & 34.2 & 94.6 & 24.5 & 30.9 & 13.1 & 3.4 & 12.2 & 0.0 & 0.0 & 100.0 \\
\hline 500 & 30 & 224.1 & 69.8 & 47.0 & 89.4 & 27.9 & 34.6 & 7.5 & 2.3 & 49.9 & 0.0 & 0.0 & 100.0 \\
\hline 500 & 60 & 215.4 & 67.1 & 49.1 & 99.8 & 31.1 & 27.1 & 5.8 & 1.8 & 61.4 & 0.0 & 0.0 & 100.0 \\
\hline
\end{tabular}

Table 6. Energy requirement and energy costs for the investigated treatments.

\begin{tabular}{ccccccccc}
\hline & \multicolumn{3}{c}{ Energy requirement $\left(\mathrm{kWh} \mathrm{ton}^{-1}\right)$} & \multicolumn{4}{c}{ Energy costs $\left(€\right.$ ton $\left.^{-1}\right)$} \\
\hline Power $(\mathrm{W})$ & $5 \mathrm{~min}$ & $18 \mathrm{~min}$ & $30 \mathrm{~min}$ & $60 \mathrm{~min}$ & $5 \mathrm{~min}$ & $18 \mathrm{~min}$ & $30 \mathrm{~min}$ & $60 \mathrm{~min}$ \\
\hline 160 & 21.3 & 76.8 & 128 & 256 & 2.6 & 9.2 & 15.4 & 30.7 \\
350 & 46.7 & 168 & 280 & 560 & 5.6 & 20.2 & 33.6 & 67.2 \\
500 & 66.7 & 240 & 400 & 800 & 8.0 & 28.8 & 48.0 & 96.0 \\
\hline
\end{tabular}

